\title{
Pregnant Women's Preferences for Men's Faces Differ Significantly from Nonpregnant Women
}

\author{
Erika Limoncin, PsyD, PhD, ${ }^{* 1}$ Giacomo Ciocca, PsyD, PhD, ${ }^{* 1}$ Giovanni Luca Gravina, MD,* \\ Eleonora Carosa, MD, PhD, ${ }^{*}$ Daniele Mollaioli, PsyD, ${ }^{*}$ Alessandro Cellerino, $\mathrm{PhD},{ }^{\dagger}$ \\ Andrea Mennucci, MD, ${ }^{\dagger}$ Stefania Di Sante, MD, ${ }^{\ddagger}$ Andrea Lenzi, MD, ${ }^{\ddagger}$ and Emmanuele A. Jannini, MD ${ }^{\star \S}$ \\ *School of Sexology, Department of Clinical, Applied and Biotechnological Sciences, University of L'Aquila, L'Aquila, \\ Italy; 'Laboratory of Biology, Scuola Normale Superiore di Pisa, Pisa, Italy; ‡Department of Experimental Medicine, \\ Sapienza University of Rome, Rome, Italy; §Endocrinology, Andrology and Medical Sexology, Department of Systems \\ Medicine, Tor Vergata University of Rome, Rome, Italy
}

DOI: $10.1111 /$ jsm.12849

\section{A B S T R A C T}

Introduction. There is evidence that women's preferences for facial characteristics in men's faces change according to menstrual phase and sexual hormones. Literature indicates that the pregnancy is characterized by a specific sexual hormonal pattern with respect to all other physiological conditions concerning the sexual hormone status during the reproductive age, configuring this physiological condition as an excellent surrogate to study how the sexual hormones may affect many of the aspects concerning the sexual behavior.

Aim. The aim of this study was to investigate pregnancy as a model of hormonal influence on women's facial preferences in short-term and long-term relationships and compare the choices of pregnant women with those of nonpregnant women.

Main Outcome Measures. Measurement of women's preferences for synthetic men's faces, morphed from hypermasculine to hypomasculine shape.

Materials and Methods. Forty-six women in the third trimester of pregnancy, and 70 nonpregnant women took part in the study. All women were shown a composite male face. The sexual dimorphism of the images was enhanced or reduced in a continuous fashion using an open-source morphing program that produced a sequence of 21 pictures of the same face warped from a feminized to a masculinized shape.

Results. Pregnant women's choices differed significantly from those of nonpregnant women. In fact, in the context of both a hypothetical short- $(M=-0.4 \pm 0.11)$ and long-term relationship $(M=-0.4 \pm 0.07)$ pregnant women showed a clear preference for a less masculine man's face than the other group (short-term: $M=0.15 \pm 0.13$; long-term: $M=-0.06 \pm 0.15 ; P<0.0001)$.

Conclusions. Women in the third trimester of pregnancy clearly prefer more feminine men's faces, distancing themselves from the choices of women in other physiological conditions concerning the sexual hormonal status during the reproductive age. However, other psychosocial variables may explain this interesting finding. Limoncin E, Ciocca G, Gravina GL, Carosa E, Mollaioli D, Cellerino A, Mennucci A, Di Sante S, Lenzi A, and Jannini EA. Pregnant women's preferences for men's faces differ significantly from nonpregnant women. J Sex Med ${ }^{* *} ;{ }^{* *}:{ }^{* *}{ }^{* *}$.

Key Words. Pregnant Women; Dimorphism; Attractiveness; Hormones

${ }^{1}$ Equal contribution. 


\section{Introduction}

$\mathrm{T}$ he human face has a central role in social life, as an important influence on judgments of the physical attractiveness of potential partners [1]. Studies of responses to human facial sexual dimorphism have yielded intriguing insights into how facial masculinity or femininity affects perceptions of other traits such as attractiveness or trustworthiness. Manipulations of sexually dimorphic facial traits in computerized faces have been used to study how facial shape influences judgments [2-5]. The most important finding was that there are correlations between facial sexual dimorphisms and ratings of attractiveness [6] and that such judgments appear to have an evolutionary basis. Men and women appear to employ somewhat different mating tactics and are attracted by different mate qualities [7]. Cross-cultural studies have shown that men give more importance to physical traits, such as the hip-waist ratio, which is associated with the female reproductive potential [8], whereas women place more value on status and positive psychological attributes $[9,10]$. These sexual differences, which have been passed down the generations, have been attributed to the differential parental investment of males and females [3,10-12].

A cost-benefit approach to how evaluation of the attractiveness of men's faces is related to sexual dimorphism has also been considered [13]. It has been suggested that women consider a set of direct and indirect benefits during the evaluation of male mate attractiveness. Indirect benefits might include heritable immunity to infectious disease, whereas direct benefits are those that directly influence the life chances of offspring, such as social and material support, or reduced risk of disease [14,15].

Biological or hormonal drive is an important factor in women's judgments of male facial features and varies according to hormonal state. Many studies have shown that evaluations of the attractiveness of men's faces vary with menstrual phase and use of contraceptive pills [14,16-19].

There is evidence that women's evaluation of what constitutes an attractive man's face shifts across the menstrual cycle, more specifically it has been demonstrated that during the ovulatory phase, women tend to prefer a more masculine face $[15,20]$. It has been suggested that this preference depends on the potential for conception and is designed to ensure that in the event of pregnancy the offspring would benefit from good paternal genes for immunocompetence [21], as averageness, symmetry, sexual dimorphism $[22,23]$, the voice, and the height [24]. In other phases of the menstrual cycle during which the woman is normally infertile, such as the luteal phase, women tend to choose more feminine men's faces, in order to select partners on the basis of characteristics that are potentially useful for the offspring care, such as cooperation and protectiveness. Although more masculine men's faces are interpreted as a guarantee of "good" genes, they might also signal negative attributes; it is known that men with more masculine faces tend to make low investments in stable relationships, owing, in some cases, to a tendency to impregnate as many women as possible.

If it is true that variations in hormonal levels influence women's judgments of what constitutes an attractive male face [25], women's preferences should change in pregnancy. It has in fact been demonstrated that pregnancy shifts women's preferences toward a less masculine face, finding which is consistent with the hypothesis that the mate preferences of pregnant women are not influenced by a need to pass on good genes to potential offspring, because they are already pregnant.

Although there is some evidence on how specific physiological conditions influence women's evaluations of men's facial attractiveness, there is still no clear data on how pregnancy may affect choice of a potential partner for a short-term (casual) or long-term (stable) relationship.

\section{Aims}

Literature indicates that the third trimester of pregnancy is characterized by a specific sexual hormonal pattern with respect to all other physiological conditions concerning the sexual hormone status during the reproductive age. This specificity configures the third trimester of pregnancy as an excellent surrogate to study how the sexual hormones may affect many of the aspects concerning the sexual behavior [26-30].

So, the aim of the study was to investigate how the pregnancy in the third trimester may bear the facial shape preference with respect to nonpregnant women, with particular emphasis on the relationship context: casual (short term) versus stable (long term). 


\section{Materials and Methods}

\section{Subjects}

The study was approved by our local ethical committee. A sample of 116 women of reproductive age (26.14-39.88 years) was recruited from students and staff of the L'Aquila university. This study was conducted in an outpatient setting, and for this reason, the evaluation of sexual hormonal profile was not actively pursued. The study population was composed of 46 pregnant women who were compared with 70 nonpregnant women. The nonpregnant women were composed of 24 women in early follicular phase (group A), 24 in ovulatory phase (group B), and 22 assuming contraceptive pills (croup C). Confirmation of ovulatory phase in the group B was obtained using an ovulatory kit (ClearBlue Ovulation Test; Procter \& Gamble Switzerland SARL, Petit-Lancy, Genève, Switzerland). Women assuming contraceptive pills declared to taken estroprogestinic contraceptive pills. None of the females in the group assuming contraceptive used progestin contraceptives in the form of intrauterine device.

Kinsey scale [31] scores based on overt behavior were used to index the exclusive heterosexuality of our sample. The women were also assessed by a clinical psychologist, using Diagnostic and Statistical Manual of Mental Disorders Fifth Edition criteria, to exclude subjects with possible mental disorders [32]. All subjects confirmed that they did not have any endocrine diseases and were not taking any recreational or prescription drugs.

Subjects were unpaid and participate in the research voluntarily. They provided written, informed consent to the scientific use of their scores before completing out the survey. The rationale of the study and the method used to produce the stimuli was explained to women after they had completed the psychophysical test.

\section{Psychophysical Test}

A consolidated protocol based on an open-source morphing program (gtkmorph) based on the $\mathrm{X}$-Morph algorithm was used $[2,33]$ to assess the women's preferences for a hypothetical short- and long-term sexual partner.

Subjects were first presented with the two most extreme faces (the most masculine and most feminine), then the cursor was placed in the middle of the time track (frame 11). The women were asked to select the frame showing the face they would find most physically attractive in a prospective short-term or long-term partner.
Subject age and face choices in both conditions were recorded.

\section{Statistical Methods}

A 5\% significance threshold was applied in all analyses. All tests were two sided and were carried out using the Monte Carlo method. The Monte Carlo method was chosen because it produces a reliable result regardless of the size, distribution, sparseness, or balance of the data. The continuous variables were normally distributed (Shapiro-Wilk test) and are presented as means with standard deviation. The multivariate analysis of covariance (MANCOVA) analysis with age, university degree, secondary degree, and stable relationship as covariates were used to measure the statistical difference between means of male facial preferences in all the study groups. Post hoc multiple pairwise comparisons were performed using the Bonferroni method.

Dichotomous variables were expressed as absolute and relative frequencies, and group differences were evaluated using a $\chi^{2}$ test with the Bonferroni correction for multiple comparisons. The impact of the condition "pregnancy" and of the other socio-demographic variables on the responses at the morphing test was measured by a stepwise multivariate linear regression analysis. In this analysis, continuous dependent variable was the morphing response, and the independent variables were age, university degree, secondary degree, stable relationship, and group pregnancy versus group nonpregnancy. Specifically, the dichotomous independent variables were coded as follow: (i) " 1 " the group named "pregnancy" and " 0 " the group named nonpregnancy; (ii) "1" women with university degree and " 0 " women without university degree; (iii) "1" women with secondary degree and " 0 " women without secondary degree; and (iv) "1" women with stable relationship and "0" women without stable relationship. All statistical analyses were performed using the SPSS $®$ statistical analysis software package, version 10.0 (IBM Corporation, Armonk, NY, USA).

\section{Results \\ Differences in Female Preferences for Dimorphic Faces among Four Groups}

Table 1 summarizes the socio-demographic characteristics of our sample. There were group differences in age but not in any of the other sociodemographic variables investigated. We asked 
Table 1 Demographic data

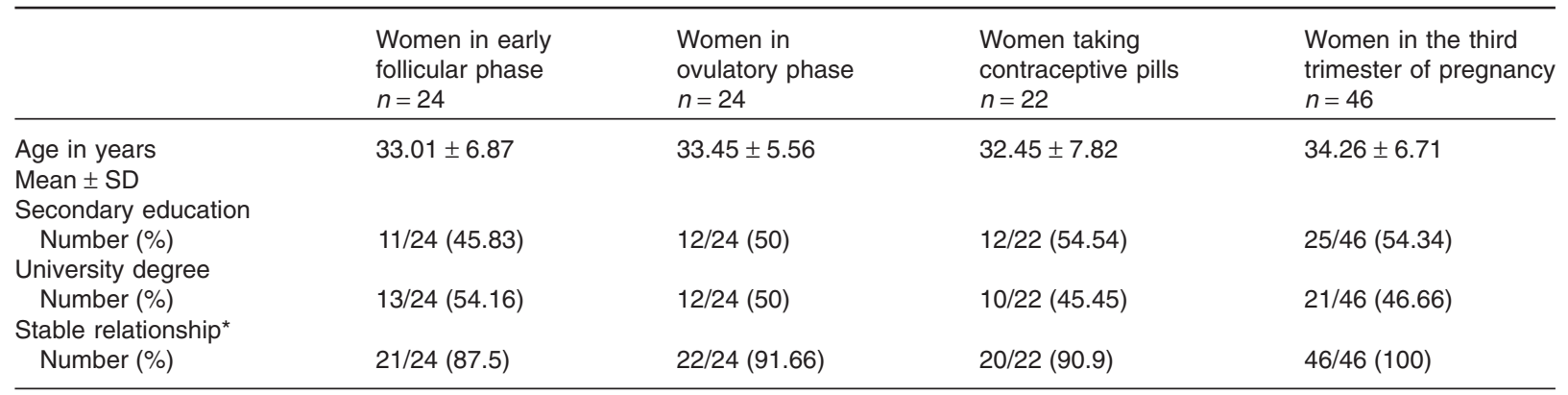

Notes: *Duration $\geq 12$ months.

women to select the face they would find most physically attractive in a short-term partner and long-term partner from a continuum of men's faces that varied with respect to sexual dimorphic features. The averaged face and the two extremes of the face continuum were the same as in Skrinda et al.'s study [24]. Based on the Kinsey scale, all females declared to be heterosexuals.

MANCOVA analysis revealed a group difference in preferred facial characteristics of both short- and long-term partners (Tables 2 and 3). Pregnant women (group D) showed a clear preference for a much less masculine man's face than the other groups when choosing a hypothetical longterm partner. This was evident in the mean values of the morphing test, pregnant women's choices $(M=-0.4 \pm 0.07)$ differed significantly from those of women in early follicular phase (group A: $M=-0.2 \pm 0.098 ; P<0.0001)$ or the ovulatory phase (group B: $M=0.1 \pm 0.08 ; P<0.0001$ ), as well as from those taking contraceptive pills (group $C$ : $M=-0.1 \pm 0.07 ; P<0.0001$ ) (Figure 1).
In the context of a hypothetical short-term or casual relationship pregnant women once again showed a clear preference for a less masculine (group B: $M=0.3 \pm 0.09$; group C: $M=0.05 \pm$ 0.072) (Figure 1).

Furthermore, the preferences of women in early follicular phase differed significantly from those of women in the ovulatory phase with respect to both short- (group A: $M=0.1 \pm 0.1$; group B: $M=0.3 \pm 0.09$ ) and long-term hypothetical partners (group A: $M=-0.2 \pm 0.098$; group B: $M=0.1 \pm 0.08 ; \quad P<0.0001)$. Finally, the analysis revealed a remarkable difference between the preferences of women taking contraceptive pills (short term: group C: $M=0.05 \pm$ 0.072; long term: group C: $M=-0.1 \pm 0.07)$ and women in the ovulatory phase (short term: group $\mathrm{B}$ : $M=0.3 \pm 0.09$; long term: group $\mathrm{B}$ : $M=0.1 \pm 0.08 ; \quad P<0.0001$ ) (Figure 1 ); women in the ovulatory phase chose more masculine faces for both short- and long-term relationships.

Table 2 Short-term partner preferences: Pairwise comparisons using MANCOVA with age, secondary education, university degree, and stable relationship as covariates

\begin{tabular}{|c|c|c|c|c|c|c|}
\hline \multirow{2}{*}{$\frac{\text { Group }}{A}$} & \multicolumn{2}{|c|}{ Pairwise comparisons } & \multirow{2}{*}{$\begin{array}{l}\text { Mean } \\
\text { difference }\end{array}$} & \multirow{2}{*}{$\begin{array}{l}\text { Std. error } \\
0.03151\end{array}$} & \multirow{2}{*}{$\begin{array}{l}P^{\dagger} \\
<0.0001\end{array}$} & \multirow{2}{*}{$\begin{array}{l}95 \% \mathrm{Cl}^{\dagger} \\
-0.3876 \text { to }-0.2182\end{array}$} \\
\hline & vs. & B & & & & \\
\hline & vs. & C & -0.09000 & 0.03214 & 0.0363 & -0.1764 to -0.003614 \\
\hline & vs. & D & 0.1950 & 0.02850 & $<0.0001$ & $0.1184-0.2716$ \\
\hline \multirow[t]{3}{*}{ B } & vs. & A & 0.3029 & 0.03151 & $<0.0001$ & $0.2182-0.3876$ \\
\hline & vs. & C & 0.2129 & 0.03169 & $<0.0001$ & $0.1277-0.2980$ \\
\hline & vs. & $\mathrm{D}$ & 0.4978 & 0.02757 & $<0.0001$ & $0.4237-0.5719$ \\
\hline \multirow[t]{3}{*}{ C } & vs. & $A$ & 0.09000 & 0.03214 & 0.0363 & $0.003614-0.1764$ \\
\hline & vs. & B & -0.2129 & 0.03169 & $<0.0001$ & -0.2980 to -0.1277 \\
\hline & vs. & D & 0.2850 & 0.02807 & $<0.0001$ & $0.2095-0.3604$ \\
\hline \multirow[t]{3}{*}{ D } & vs. & $A$ & -0.1950 & 0.02850 & $<0.0001$ & -0.2716 to -0.1184 \\
\hline & vs. & B & -0.4978 & 0.02757 & $<0.0001$ & -0.5719 to -0.4237 \\
\hline & vs. & $\mathrm{C}$ & -0.2850 & 0.02807 & $<0.0001$ & -0.3604 to -0.2095 \\
\hline
\end{tabular}

Notes: †Bonferroni corrected; A: Women in early follicular phase; B: Women in ovulatory phase; C: Women taking contraceptive pills; D: Women in the third trimester of pregnancy. 
Table 3 Long-term partner preferences: Pairwise comparisons using MANCOVA with age, secondary education, university degree, and stable relationship as covariates

\begin{tabular}{|c|c|c|c|c|c|c|}
\hline \multirow{2}{*}{$\frac{\text { Group }}{\mathrm{A}}$} & \multicolumn{2}{|c|}{ Pairwise comparisons } & \multirow{2}{*}{$\begin{array}{l}\begin{array}{l}\text { Mean } \\
\text { difference }\end{array} \\
-0.1763\end{array}$} & \multirow{2}{*}{$\begin{array}{l}\text { Std. error } \\
0.03049\end{array}$} & \multirow{2}{*}{$\frac{P^{\dagger}}{<0.0001}$} & \multirow{2}{*}{$\frac{95 \% \mathrm{Cl}^{\dagger}}{-0.2582 \text { to }-0.09434}$} \\
\hline & vs. & B & & & & \\
\hline & vs. & $\mathrm{C}$ & 0.06742 & 0.03110 & 0.1941 & -0.01616 to 0.1510 \\
\hline & vs. & D & 0.5108 & 0.02758 & $<0.0001$ & $0.4367-0.5849$ \\
\hline \multirow[t]{3}{*}{ B } & vs. & A & 0.1763 & 0.03049 & $<0.0001$ & $0.09434-0.2582$ \\
\hline & vs. & C & 0.2437 & 0.03067 & $<0.0001$ & $0.1613-0.3261$ \\
\hline & vs. & D & 0.6871 & 0.02667 & $<0.0001$ & $0.6154-0.7588$ \\
\hline \multirow[t]{3}{*}{ C } & vs. & A & -0.06742 & 0.03110 & 0.1941 & -0.1510 to 0.01616 \\
\hline & vs. & B & -0.2437 & 0.03067 & $<0.0001$ & -0.3261 to -0.1613 \\
\hline & vs. & $\mathrm{D}$ & 0.4434 & 0.02716 & $<0.0001$ & $0.3704-0.5164$ \\
\hline \multirow[t]{3}{*}{ D } & vs. & A & -0.5108 & 0.02758 & $<0.0001$ & -0.5849 to -0.4367 \\
\hline & vs. & $B$ & -0.6871 & 0.02667 & $<0.0001$ & -0.7588 to -0.6154 \\
\hline & vs. & C & -0.4434 & 0.02716 & $<0.0001$ & -0.5164 to -0.3704 \\
\hline
\end{tabular}

Notes: ${ }^{\dagger}$ Bonferroni corrected; A: Women in early follicular phase; B: Women in ovulatory phase; C: Women taking contraceptive pills; D: Women in the third trimester of pregnancy.

The preferences of women in early follicular phase and women taking contraceptive pills were similar with respect to both short-term (group A: $M=0.1 \pm 0.1 ;$ group $\mathrm{C}: M=0.05 \pm 0.072 ; P=$ 0.466 ) and long-term (group A: $M=-0.2 \pm 0.098$; group $\mathrm{C}: M=-0.1 \pm 0.07 ; P=0.063)$ partners.

\section{Pregnancy Is Associated with a More Feminized} Male Face Preference

MANCOVA analysis revealed a difference between pregnant and nonpregnant women for facial preferences of both short- and long-term partners (Tables 4 and 5). In the context of a hypothetical short-term or casual relationship pregnant women showed a clear preference for a less masculine man's face $(M=-0.4 \pm 0.11)$ than the other group $(M=0.15 \pm 0.13)$ (Figure 2).

Pregnant women showed a clear preference for a much less masculine man's face than the other group when choosing a hypothetical long-term partner (Figure 2). This was evident in the mean values of the morphing test. In fact pregnant
Figure 1 Facial preferences of the four groups. The vertical axis indicates degree of geometric sexual dimorphism. Zero represents average masculinity; positive values correspond to more masculine faces. Data are represented as means and standard deviations. ${ }^{\star} P<0.0001$.

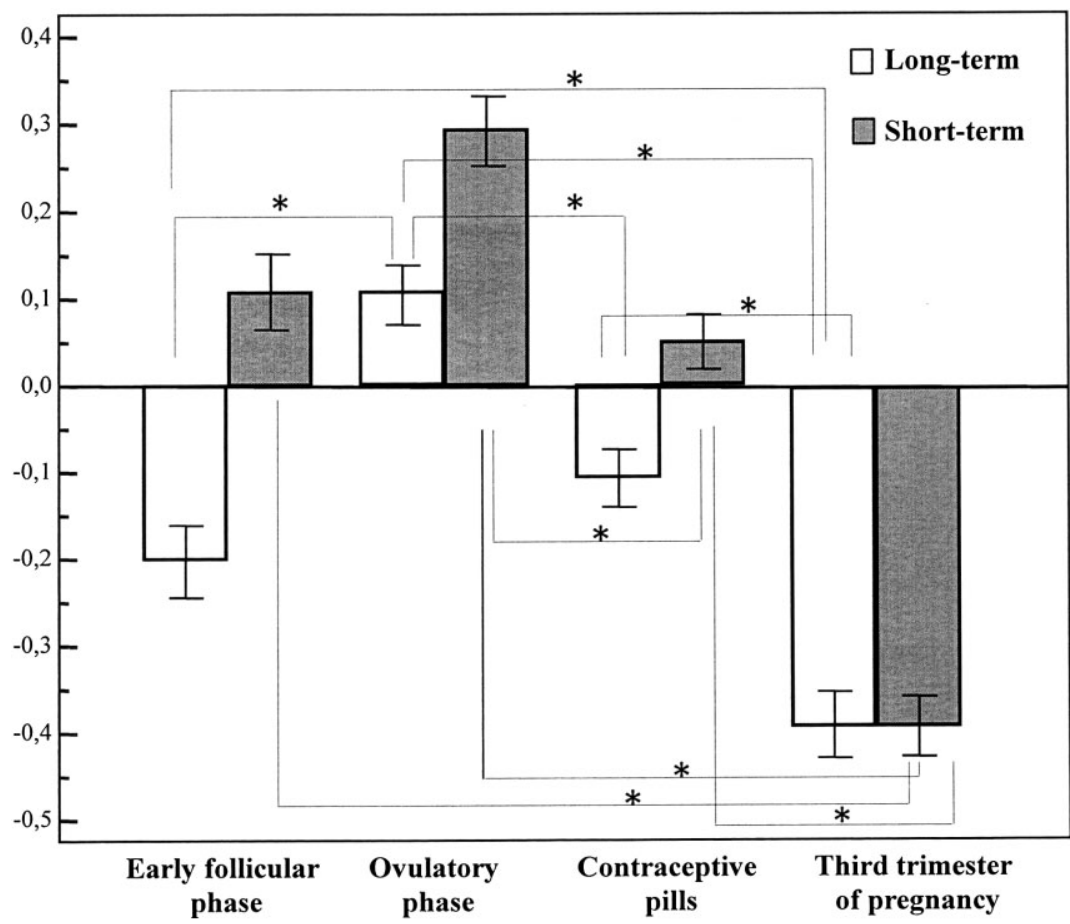

J Sex Med **;****_** 
Table 4 MANCOVA analysis for facial preferences of pregnant vs. nonpregnant women (short-term relationship)

\begin{tabular}{lllll}
\hline Tests of between-subjects effects & & & \\
\hline Covariates & Sum of squares & Mean square & $F$ & $P$ \\
Age & 0.0236 & 0.0236 & 1.148 & 0.286 \\
Secondary education & 0.00527 & 0.00527 & 0.257 & 0.613 \\
Stable relationship & 0.0430 & 0.0430 & 2.094 & 0.151 \\
University degree & 0.0338 & 0.0338 & 1.645 & 0.202 \\
\hline Post hoc pairwise comparisons & & & & \\
\hline Study groups & Mean difference & Std. error & $P$ & $95 \% \mathrm{Cl}$ \\
$\quad$ Nonpregnancy vs. pregnancy & -0.3379 & 0.02861 & $<0.0001$ & 0.2812 to 0.3946 \\
\hline
\end{tabular}

Table 5 MANCOVA analysis for facial preferences of pregnant vs. nonpregnant women (long-term relationship)

\begin{tabular}{|c|c|c|c|c|c|}
\hline \multicolumn{6}{|c|}{ Tests of between-subjects effects } \\
\hline Covariates & Sum of squares & DF & Mean square & $F$ & $P$ \\
\hline Age & 0.0337 & 1 & 0.0337 & 2.098 & 0.150 \\
\hline Secondary education & 0.0197 & 1 & 0.0197 & 1.231 & 0.270 \\
\hline Stable relationship & 0.106 & 1 & 0.106 & 6.585 & 0.012 \\
\hline University degree & 0.0160 & 1 & 0.0160 & 0.994 & 0.321 \\
\hline \multicolumn{6}{|l|}{ Post hoc pairwise comparisons } \\
\hline Study groups & Mean difference & Std. error & $P$ & $95 \% \mathrm{Cl}$ & \\
\hline Nonpregnancy vs. pregnancy & -0.5661 & 0.02530 & $<0.0001$ & 0.5160 to 0.6162 & \\
\hline
\end{tabular}

women's choices $(M=-0.4 \pm 0.07)$ differed significantly from those of nonpregnant $(M=-0.06 \pm$ 0.15; $P<0.0001$ ) (Figure 2).

As shown in Table 6, the regression analysis indicates that the only variable retained in the model after a stepwise approach was the condition "pregnancy." Interestingly, less dimorphic facial preferences were significantly associated with pregnancy state, and more dimorphic facial preferences were significantly associated with nonpregnancy state for both short- and long-term relationships $(P<0.0001)$. The $R^{2}$ values indicated that the

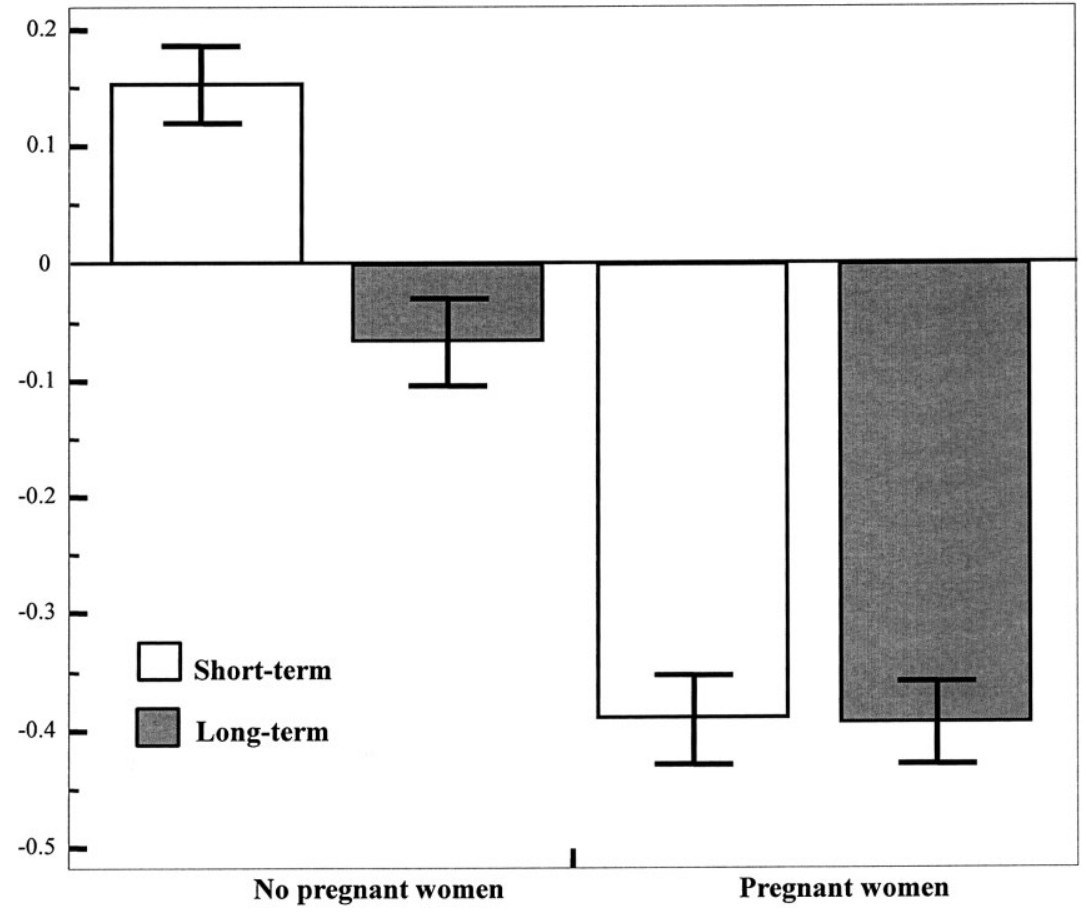

Figure 2 Facial preferences of pregnant vs. nonpregnant women. The vertical axis indicates degree of geometric sexual dimorphism. Zero represents average masculinity; positive values correspond to more masculine faces. Data are represented as means and standard deviations. ${ }^{*} P<0.0001$. 
Table 6 Multivariate linear regression analysis

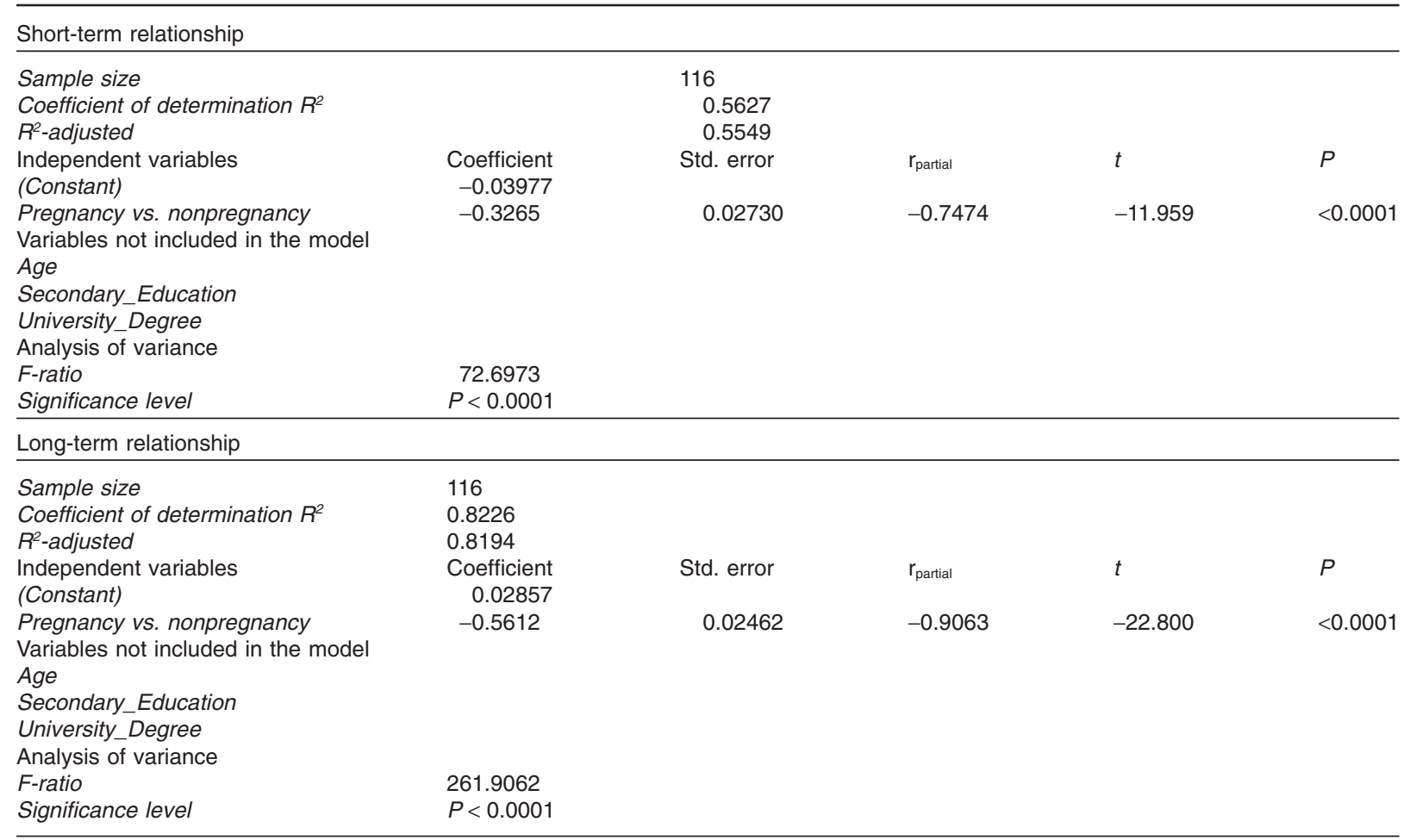

$55.49 \%$ and the $81.94 \%$ of different choices in matter of short- and long-term relationship were imputable to be or not to be in a pregnant status.

\section{Discussion}

Our results provide evidence about the facial characteristics that pregnant women find attractive in potential male partners and suggest that during the gestational period sex hormone, together with other psycho-relational variables, may play a role in determining partner preferences. Hormonal fluctuations during the female menstrual cycle are related to changes in women's preferences for masculine characteristics in men's faces $[14,34]$. Similarly, testosterone has an impact in men's judgments of facial attractiveness, irrespective of sexual orientation $[33,35]$.

This study has demonstrated that shifts in female sexual interest are completely abolished during pregnancy. Pregnant women have a clear preference for less masculine men's faces in both short- and long-term hypothetical partners than women who are not pregnant. This is the largest effect observed across all the studies published to date on women's choices of men's faces $[1,3,14]$ with particular hormonal status $[14-16,34,36]$. In our study, pregnancy seems to be the primary factor affecting female mating strategies. Pregnant women's preferences in men's faces are different from those of women in the ovulatory phase, women taking contraceptive pills, and women in the early follicular phase. Interestingly when nonpregnant women were pooled and compared with pregnant women, the male facial preferences significantly differed between these two groups. However, although an obvious explanation of these differences may be attributable to the different hormonal status characterising the pregnancy, it is also important to highlight that other psychological variables may directly bear on female sexual desire, well before on mating strategies. This is, for example, the case of a common fear during the third trimester of pregnancy to harm with sexual intercourse the fetus [37-39]. In the light of this consideration, pregnant women might prefer less dimorphic male faces, which are considered less aggressive.

High progesterone levels, which are typical of pregnancy, are associated with preference for less masculine faces [15], a finding confirmed in this study. A similar directly progesterone-related effect has also been observed in the luteal phase [15]; this is not surprising as the biological aim of the 
progesterone-dependent luteal phase is to prepare the body, and probably also adjust behavior, for a possible or actual pregnancy [16]. These progesterone-related data may be interpreted from evolutionary perspective, according to which hormonal changes shift preferences from the prezygotic preference for cues to "good" genes (reflected in a strong preference for masculine facial characteristics) to cues for characteristics that may be beneficial in caring for offspring. The hypomasculine preferences of our pregnant women may be evidence of the placing of higher value on direct benefits, such as social and material support, paternal care-giving, or reduced risk of disease $[9,15]$. In this regard, another important study found that during the menstrual phase women are most attracted by direct benefits, whereas indirect benefits are preferred during the fertile phase [36].

Cultural values attribute traits that are advantageous in child-rearing - such as fidelity, lower aggressiveness, and higher investment in stable relationships [40-42] — to men with more feminine facial characteristics, whereas very masculine men's faces are associated with personality traits considered less useful, such as dominance and a tendency to get involved only in short-term relationships.

Our data were consistent with the body of evidence that women exhibit a stronger preference for masculine facial characteristics during the ovulatory phase of the menstrual cycle. In this phase, when the chance of conception is greatest, women seem to opt for indirect benefits, preferring putative indicators of "good" genes or health [14].

Although the peak in fertility during the ovulatory phase influences women's preferences for masculine characteristics in men's faces, there is less evidence that preferences are fertility related in women taking contraceptive pills [17]. Our results are consistent with previous theories of how taking contraceptive pills affects mating strategy. Use of contraceptive pills and the associated hormonal changes appear to shift women's preferences away from partners with more masculine facial characteristics, toward characteristics presumed to be associated with greater cooperation. Studies of preferences in men's faces in postmenopausal women and in prepuberty girls $[19,34]$ have provided further evidence that hormonal state influences mating strategies; both these groups tended to prefer less masculine men's faces. Similarly, in our study, the women in early follicular phase and those taking contraceptive pills also showed a preference for less masculine men's faces. We suggest that this pattern of preferences for masculine facial characteristics in male partners is related to reproductive potential.

An association between low reproductive potential and lower preference for masculine facial characteristics in potential male partners was also evident in the choices of pregnant women. During pregnancy, women need specific partners with specific attributes, as security and fidelity, and unconsciously search out men with more delicate facial features, which are assumed to indicate tenderness, rejecting men with facial characteristics associated with strong, hard masculinity [18]. Women's mating strategies and sexual behavior are influenced by hormonal state and changes in hormonal state [43] throughout the lifecycle [44-46].

The lack of a psychometric of sexual functioning and other psychological and relationship variables as information on the actual partner's facial dimorphism, together with the absence of an evaluation of a specific hormonal status, may represent an important limitation of this study. Psychological characteristics may be an intervening variable in the choices to the morphing test. In addition, other information regarding the women's health status, such as hypertension, or gestational diabetes, might bear on the choice for a less or more dimorphic male face. Future researches will be necessary to investigate the association of women's health status and the searching for male indirect or direct benefits.

\section{Conclusions}

Pregnancy configures as an excellent surrogate model to study how the sexual hormones may affect many of the aspects concerning the sexual behavior. In this regard, women in the third trimester of pregnancy clearly prefer more feminine men's faces, distancing themselves from the choices of women in other physiological conditions concerning the sexual hormone status during the reproductive age. However, other psychosocial variables may explain this interesting finding.

Future research will investigate relationships between psychological and neuro-endocrinological variables, and the influence of psychological factors and specific hormonal states on women's preference for specific male facial characteristics.

Corresponding Author: Emmanuele A. Jannini, MD, Department of Systems Medicine, Tor Vergata University of Rome, Via Montpellier 1, 00131 Roma, Italy. Tel: +39 0862-433-530; Fax: +39 0862-433-523; E-mail: eajannini@gmail.com 
Conflict of Interest: The author(s) report no conflicts of interest.

\section{Statement of Authorship}

Category 1

(a) Conception and Design

Emmanuele A. Jannini; Andrea Mennucci; Erika Limoncin; Giacomo Ciocca; Alessandro Cellerino

(b) Acquisition of Data

Emmanuele A. Jannini

(c) Analysis and Interpretation of Data

Erika Limoncin; Giacomo Ciocca; Giovanni Luca Gravina

\section{Category 2}

(a) Drafting the Article

Erika Limoncin; Giacomo Ciocca; Giovanni Luca Gravina

(b) Revising It for Intellectual Content Emmanuele A. Jannini

\section{Category 3}

(a) Final Approval of the Completed Article

Erika Limoncin; Emmanuele A. Jannini; Giovanni Luca Gravina; Giacomo Ciocca; Eleonora Carosa; Stefania Di Sante; Daniele Mollaioli; Andrea Lenzi; Alessandro Cellerino; Andrea Mennucci

\section{References}

1 Johnston VS, Solomon CJ, Gibson SJ, Pallares-Bejarano A. Human facial beauty: Current theories and methodologies. Arch Facial Plast Surg 2003;5:371-7.

2 Perrett DI, Lee KJ, Penton-Voak I, Rowland D, Yoshikawa S, Burt DM, Henzi SP, Castles DL, Akamatsu S. Effects of sexual dimorphism on facial attractiveness. Nature 1998;394:884-7. [Epub 1998/09/11].

3 Little AC, Jones BC, DeBruine LM. The many faces of research on face perception. Philos Trans R Soc Lond B Biol Sci 2011;366:1634-7. [Epub 2011/05/04].

4 Penton-Voak IS, Jones BC, Little AC, Baker S, Tiddeman B, Burt DM, Perrett DI. Symmetry, sexual dimorphism in facial proportions and male facial attractiveness. Proc R Soc Lond B Biol Sci 2001;268:1617-23.

5 Sprengelmeyer R, Lewis J, Hahn A, Perrett DI. Aesthetic and incentive salience of cute infant faces: Studies of observer sex, oral contraception and menstrual cycle. PLoS ONE 2013; 8:e65844. [Epub 2013/06/05].

6 Smith F, Jones B, DeBruine L, Little A. Interactions between masculinity-femininity and apparent health in face preferences. Behav Ecol 2008;20:441-5.

7 Cornwell RE, Law Smith MJ, Boothroyd LG, Moore FR, Davis HP, Stirrat M, Tiddeman B, Perrett DI. Reproductive strategy, sexual development and attraction to facial characteristics. Philos Trans R Soc Lond B Biol Sci 2006;361:2143-54. [Epub 2006/11/23].

8 Bleske-Rechek A, Kolb CM, Stern AS, Quigley K, Nelson LA. Face and body: Independent predictors of women's attractiveness. Arch Sex Behav 2014;43:1355-65. [Epub 2014/05/ 17].

9 Buss D. Evolutionary psychology: The new science of the mind. New York: Pearson Education, Inc; 1999.
10 Schmitt DP, Alcalay L, Allik J, Angleitner A, Ault L, Austers I, Bennett KL, Bianchi G, Boholst F, Borg Cunen MA, Braeckman J, Brainerd EG 2nd, Caral LG, Caron G, Casullo MM, Cunningham M, Daibo I, De Backer C, De Souza E, Diaz-Loving R, Diniz G, Durkin K, Echegaray M, Eremsoy E, Euler HA, Falzon R, Fisher ML, Foley D, Fry DP, Fry S, Ghayur MA, Golden DL, Grammer K, Grimaldi L, Halberstadt J, Haque S, Herrera D, Hertel J, Hoffmann H, Hooper D, Hradilekova Z, Hudek-Kene-evi J, Jaafar J, Jankauskaite M, Kabangu-Stahel H, Kardum I, Khoury B, Kwon H, Laidra K, Laireiter AR, Lakerveld D, Lampert A, Lauri M, Lavallée M, Lee SJ, Leung LC, Locke KD, Locke V, Luksik I, Magaisa I, Marcinkeviciene D, Mata A, Mata R, McCarthy B, Mills ME, Mkhize NJ, Moreira J, Moreira S, Moya M, Munyae M, Noller P, Opre A, Panayiotou A, Petrovic N, Poels K, Popper M, Poulimenou M, P'yatokha V, Raymond M, Reips UD, Reneau SE, Rivera-Aragon S, Rowatt WC, Ruch W, Rus VS, Safir MP, Salas S, Sambataro F, Sandnabba KN, Schulmeyer MK, Schütz A, Scrimali T, Shackelford TK, Shaver PR, Sichona F, Simonetti F, Sineshaw T, Sookdew R, Speelman T, Spyrou S, Sümer HC, Sümer N, Supekova M, Szlendak T, Timmermans B, Tooke W, Tsaousis I, Tungaraza FS, van Overwalle F, Vandermassen G, Vanhoomissen T, Vanwesenbeeck I, Vasey PL, Verissimo J, Voracek M, Wan WW, Wang TW, Weiss P, Wijaya A, Woertman L, Youn G, Zupanèiè A; International Sexuality Description Project. Patterns and universals of mate poaching across 53 nations: The effects of sex, culture, and personality on romantically attracting another person's partner. J Pers Soc Psychol 2004;86:560-84. [Epub 2004/04/01].

11 Little AC, Burt DM, Penton-Voak IS, Perrett DI. Selfperceived attractiveness influences human female preferences for sexual dimorphism and symmetry in male faces. Proc R Soc Lond B Biol Sci 2001;268:39-44.

12 Rhodes G, Chan J, Zebrowitz LA, Simmons LW. Does sexual dimorphism in human faces signal health? Proc R Soc Lond B Biol Sci 2003;270(1 suppl):S93-5.

13 Little AC, Hancock PJ. The role of masculinity and distinctiveness in judgments of human male facial attractiveness. Br J Psychol 2002;93(Pt 4):451-64.

14 Little AC, Burriss RP, Petrie M, Jones BC, Roberts SC. Oral contraceptive use in women changes preferences for male facial masculinity and is associated with partner facial masculinity. Psychoneuroendocrinology 2013;38:1777-85. [Epub 2013/03/27].

15 Jones BC, Perrett DI, Little AC, Boothroyd L, Cornwell RE, Feinberg DR, Tiddeman BP, Whiten S, Pitman RM, Hillier SG, Burt DM, Stirrat MR, Law Smith MJ, Moore FR. Menstrual cycle, pregnancy and oral contraceptive use alter attraction to apparent health in faces. Proc Biol Sci 2005;272:347-54. [Epub 2005/03/01].

16 DeBruine LM, Jones BC, Perrett DI. Women's attractiveness judgments of self-resembling faces change across the menstrual cycle. Horm Behav 2005;47:379-83. [Epub 2005/03/22].

17 Penton-Voak IS, Perrett DI, Castles DL, Kobayashi T, Burt DM, Murray LK, Minamisawa R. Menstrual cycle alters face preference. Nature 1999;399:741-2. [Epub 1999/07/03].

18 Koscinski K. Life history of female preferences for male faces: A comparison of pubescent girls, nonpregnant and pregnant young women, and middle-aged women. Hum Nat 2011; 22:416-38. [Epub 2012/03/06].

19 Koscinski K. Facial preferences in early adolescent girls: Pubertal maturity predicts preferences maturity. Coll Antropol 2013;37:735-43. [Epub 2013/12/07].

20 Anthony C, Little BCJ, DeBruine LM. Preferences for variation in masculinity in real male faces change across the menstrual cycle: Women prefer more masculine faces when they are more fertile. Pers Individ Dif 2008;45:478-582. 
21 Roberts SC, Little AC. Good genes, complementary genes and human mate preferences. Genetica 2008;132:309-21. [Epub 2007/07/14].

22 Rhodes G, Peters M, Lee K, Morrone MC, Burr D. Higherlevel mechanisms detect facial symmetry. Proc Biol Sci 2005;272:1379-84. [Epub 2005/07/12].

23 Rhodes G. The evolutionary psychology of facial beauty. Annu Rev Psychol 2006;57:199-226. [Epub 2005/12/02].

24 Skrinda I, Krama T, Kecko S, Moore FR, Kaasik A, Meija L, Lietuvietis V, Rantala MJ, Krams I. Body height, immunity, facial and vocal attractiveness in young men. Naturwissenschaften 2014;101:1017-25. [Epub 2014/10/19].

25 Johnston VS, Hagel R, Franklin M, Fink B, Grammer K. Male facial attractiveness-Evidence for hormone-mediated adaptive design. Evol Hum Behav 2001;22:251-67.

26 Galazka I, Drosdzol-Cop A, Naworska B, Czajkowska $M$, Skrzypulec-Plinta V. Changes in the sexual function during pregnancy. J Sex Med 2014;12:445-54. [Epub 2014/11/08].

27 Hanafy S, Srour NE, Mostafa T. Female sexual dysfunction across the three pregnancy trimesters: An Egyptian study. Sex Health 2014;11:240-3. [Epub 2014/06/13].

28 Liu HL, Hsu P, Chen KH. Sexual activity during pregnancy in Taiwan: A qualitative study. Sex Med 2013;1:54-61. [Epub 2014/10/31].

29 Pauls RN, Occhino JA, Dryfhout VL. Effects of pregnancy on female sexual function and body image: A prospective study. J Sex Med 2008;5:1915-22. [Epub 2008/06/13].

30 Fleming AS, Ruble D, Krieger H, Wong PY. Hormonal and experiential correlates of maternal responsiveness during pregnancy and the puerperium in human mothers. Horm Behav 1997;31:145-58. [Epub 1997/04/01].

31 Kinsey A, Pomeroy WB, Martin CE. Sexual behavior in the human male. Philadelphia, PA: W.B. Saunders; 1948.

32 APA. Diagnostic and statistical manual of mental disorders. 5th edition. Washington, DC: American Psychiatric Association; 2013.

33 Ciocca G, Limoncin E, Cellerino A, Fisher AD, Gravina GL, Carosa E, Mollaioli D, Valenzano DR, Mennucci A, Bandini E, Di Stasi SM, Maggi M, Lenzi A, Jannini EA. Gender identity rather than sexual orientation impacts on facial preferences. J Sex Med 2014;[Epub 2014/07/30].

34 Little AC, Saxton TK, Roberts SC, Jones BC, Debruine LM, Vukovic J, Perrett DI, Feinberg DR, Chenore T. Women's preferences for masculinity in male faces are highest during reproductive age range and lower around puberty and postmenopause. Psychoneuroendocrinology 2010;35:912-20. [Epub 2010/01/12].
35 Glassenberg AN, Feinberg DR, Jones BC, Little AC, Debruine LM. Sex-dimorphic face shape preference in heterosexual and homosexual men and women. Arch Sex Behav 2010;39:1289-96. [Epub 2009/10/16].

36 Jones BC, Little AC, Boothroyd L, Debruine LM, Feinberg DR, Smith MJ, Cornwell RE, Moore FR, Perrett DI. Commitment to relationships and preferences for femininity and apparent health in faces are strongest on days of the menstrual cycle when progesterone level is high. Horm Behav 2005;48:283-90. [Epub 2005/06/28].

37 Lowenstein L, Mustafa S, Burke Y. Pregnancy and normal sexual function. Are they compatible? J Sex Med 2013;10: 621-2. [Epub 2013/03/06].

38 Corbacioglu A, Bakir VL, Akbayir O, Cilesiz Goksedef BP, Akca A. The role of pregnancy awareness on female sexual function in early gestation. J Sex Med 2012;9:1897-903. [Epub 2012/04/25].

39 Sagiv-Reiss DM, Birnbaum GE, Safir MP. Changes in sexual experiences and relationship quality during pregnancy. Arch Sex Behav 2012;41:1241-51. [Epub 2011/09/15].

40 Quist MC, Watkins CD, Smith FG, Little AC, Debruine LM, Jones BC. Sociosexuality predicts women's preferences for symmetry in men's faces. Arch Sex Behav 2012;41:1415-21. [Epub 2011/09/02].

41 Scheib JE, Gangestad SW, Thornhill R. Facial attractiveness, symmetry and cues of good genes. Proc R Soc Lond B Biol Sci 1999;266:1913-7.

42 Jones BC, DeBruine LM, Little AC, Burriss RP, Feinberg DR. Social transmission of face preferences among humans. Proc Biol Sci 2007;274:899-903. [Epub 2007/01/26].

43 Caruso S, Agnello C, Malandrino C, Lo Presti L, Cicero C, Cianci S. Do hormones influence women's sex? Sexual activity over the menstrual cycle. J Sex Med 2014;11:211-21. [Epub 2013/12/19].

44 Prasad A, Mumford SL, Buck Louis GM, Ahrens KA, Sjaarda LA, Schliep KC, Perkins NJ, Kissell KA, Wactawski-Wende J, Schisterman EF. Sexual activity, endogenous reproductive hormones and ovulation in premenopausal women. Horm Behav 2014;66:330-8. [Epub 2014/06/24].

45 Ringa V, Diter K, Laborde C, Bajos N. Women's sexuality: From aging to social representations. J Sex Med 2013;10: 2399-408. [Epub 2013/07/31].

46 Serati M, Salvatore S, Siesto G, Cattoni E, Zanirato M, Khullar V, Cromi A, Ghezzi F, Bolis P. Female sexual function during pregnancy and after childbirth. J Sex Med 2010;7:278290. [Epub 2010/07/16]. 